\title{
Increasing cloudiness in Arctic damps the increase in phytoplankton primary production due to sea ice receding
}

\author{
S. Bélanger ${ }^{1}$, M. Babin ${ }^{2}$, and J.-É. Tremblay ${ }^{2}$ \\ 'Université du Québec à Rimouski, Département de Biologie, Chimie et Géographie and \\ BORÉAS, 300 allée des Ursulines, Rimouski, Québec, G5L 3A1, Canada \\ ${ }^{2}$ Takuvik Joint International Laboratory (CNRS \& ULaval), Département de Biologie, \\ Québec-Océan and Arcticnet, Université Laval, Pavillon Alexandre-Vachon, 1045, av. de la \\ Médecine, Québec (Québec), G1V 0A6, Canada \\ Correspondence to: S. Bélanger (simon belanger@uqar.ca)
}

\section{Supplementary Information}

\section{Arctic and sub-Arctic Seas}

The regional analysis was carried on by integrating the data within the limits of oceans and seas defined by the International Hydrographic Organization (IHO) (1953). All seas infested by sea ice or above the Arctic Circle were considered in the analysis (Fig. S1). 


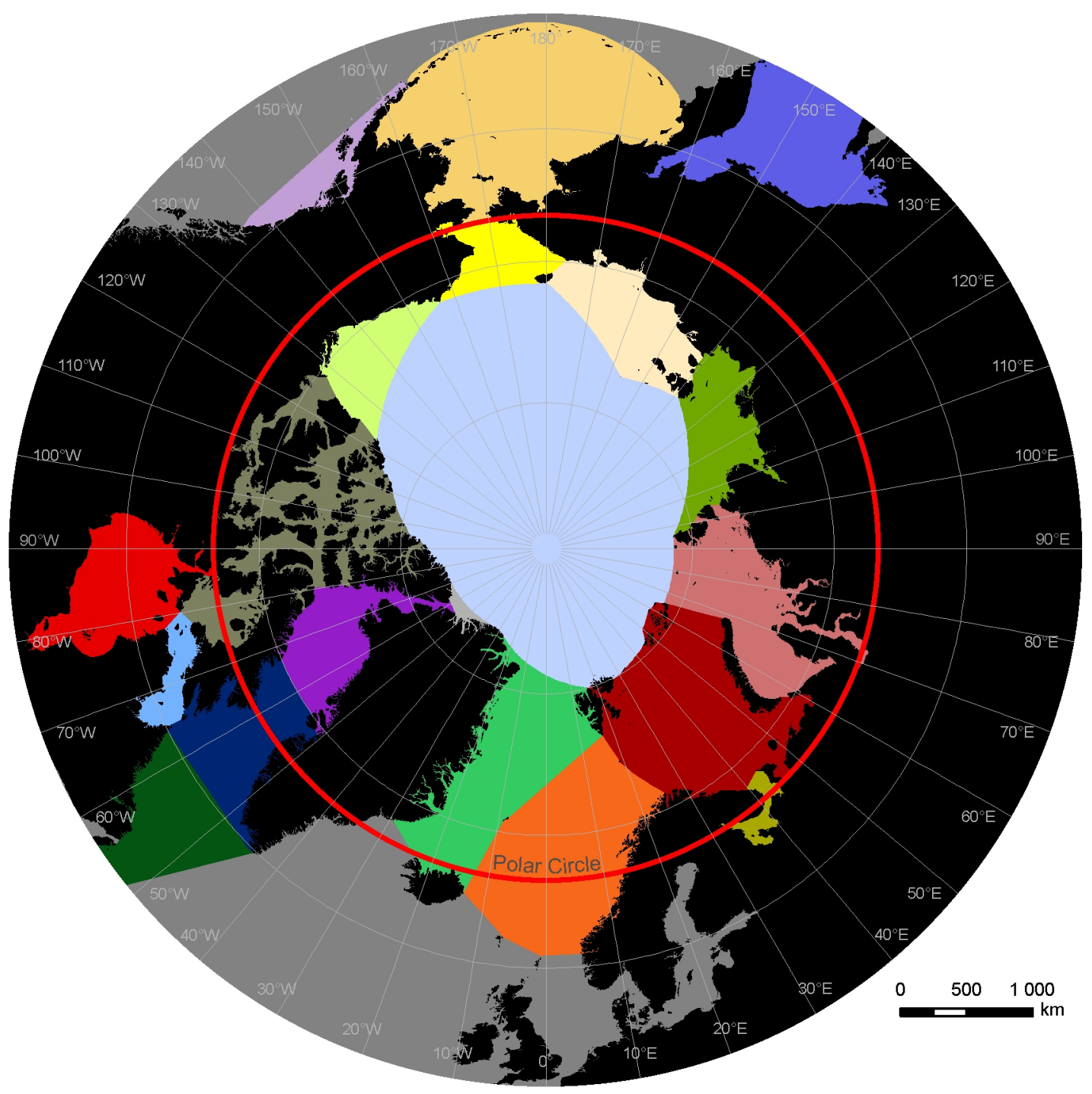

Arctic and Sub-Arctic Seas

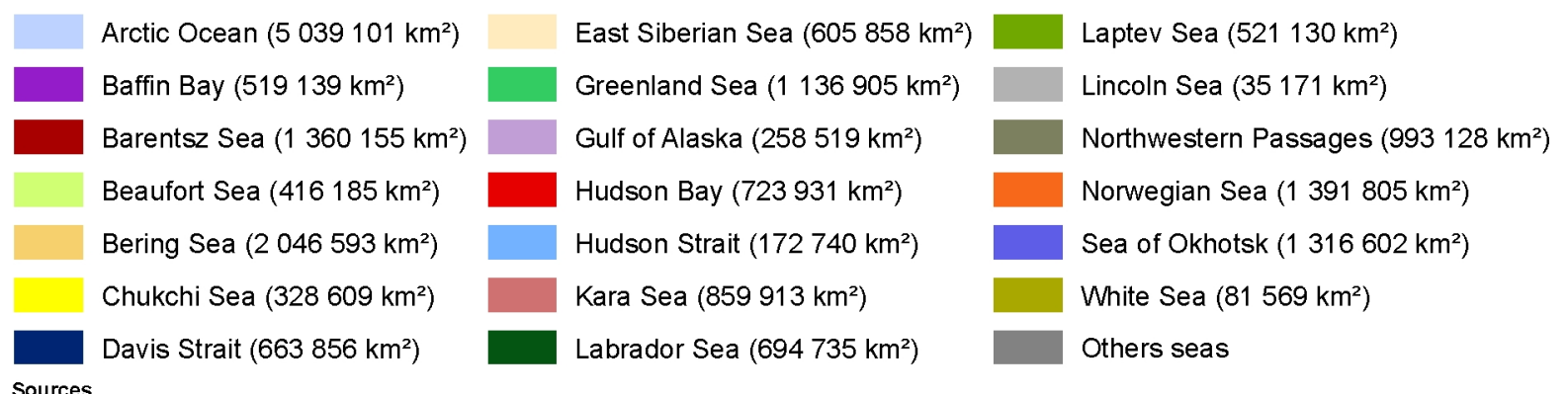
Sources

Seas: International Hydrographic Organization, 1953 Realisation : Marie-Andrée Roy, UQAR, juin 2011

Figure S1 - Limits of Oceans and Seas considered as Arctic and sub-Arctic (IHO, 1953). The area of each sea was calculated using ArcMap 9.0 (ESRI). 


\section{Relationship between depth-integrated primary production and satellite-derived ocean optical properties}

Platt and Sathyendranath (1993) demonstrated, using a dimensional analysis, that most depth-integrated primary production (PP) model assuming homogenous ocean can be generalized by a simple expression (eq. 5) that shares a common dependency to CHL/KPAR. Here photosynthetically usable radiation (PUR) was used instead of PAR, so our PP model is proportional to CHL/KPUR. This dependency can also be demonstrated mathematically by integrating eq 1 with some assumptions. Here daily PP is calculated using

$P P=C H L \cdot P_{m}^{B} \int_{z=0}^{\infty}\left(1-e^{-\frac{P U R(0-) \exp \left(-K_{P U R} \cdot z\right)}{E_{k}}}\right) d z$

where CHL is the chlorophyll $a$ concentration, $P_{m}^{B}$ is the light-saturated CHL-normalized carbon fixation rate (in $\mathrm{mg} \mathrm{C}\left(\mathrm{mg} \mathrm{CHL}^{-1} \mathrm{~h}^{-1}\right)$, and $E_{k}$ the saturation irradiance (mol photon $\left.\mathrm{m}^{-2} \mathrm{~s}^{-1}\right)$.

The factor $\left(1-e^{-\frac{P U R(0-) \exp \left(-K_{P U R} z\right)}{E_{k}}}\right)$ tends to decrease exponentially with depth following the exponential attenuation of the downwelling scalar irradiance (i.e. $\left.\exp \left(-K_{P U R} \cdot z\right)\right)$. The depth integration of the factor $\left(1-e^{-\frac{P U R(0-) \exp \left(-K_{P U R} \cdot z\right)}{E_{k}}}\right)$ is also proportional to the irradiance just below the sea surface (i.e. PUR(0-)). As in eq. 5, the non-linearity of the P vs I curves can be replaced by the factor $\mathrm{f}(\mathrm{PUR})$, which includes the variability of $E_{k}$. Thus, eq. S1 can be simplified as

$$
P P \approx C H L \cdot P_{m}^{B} \cdot f(P U R) \int_{z=0}^{\infty} P U R(0-) \exp \left(-K_{P U R} \cdot z\right) d z
$$

We can put the sub-surface irradiance outside the integral, leading to

$$
P P \approx C H L \cdot P_{m}^{B} \cdot P U R(0-) \cdot f(P U R) \int_{z=0}^{\infty} \exp \left(-K_{P U R} \cdot z\right) d z
$$

Integrating the equation yield:

$$
\begin{aligned}
& P P \approx C H L \cdot P_{m}^{B} \cdot P U R(0-) f(P U R) \mid{ }_{0}^{\infty} \frac{\exp \left(-K_{P U R} \cdot z\right)}{-K_{P U R}} d z \\
& P P \approx C H L \cdot P_{m}^{B} \cdot P U R(0-) f(P U R)\left(\frac{1}{K_{P U R}}\right)
\end{aligned}
$$

PP can be normalized to PUR(0-) (PP*) in order to remove the dependency to surface irradiance:

$$
\frac{P P}{P U R(0-)} \approx P_{m}^{B} \cdot f(P U R)\left(\frac{C H L}{K_{P U R}}\right)
$$




\section{References}

International Hydrographic Organization (IHO): Limits of Oceans and Seas, International Hydrographic Organization., Bremerhaven, PANGAEA, 1953.

Platt, T., and Sathyendranath, S.: Estimators of Primary Production for Interpretation of Remotely Sensed Data on Ocean Color. J. Geophys. Res., 98 (C8): 14561-14576, 1993. 